\title{
Pengukuran Konduktivitas Cairan Berbasis Mikrokontroler AT89C2051
}

\author{
Gita Indah Hapsari ${ }^{1}$, Roy Chaidir ${ }^{2}$ \\ ${ }^{1,2}$ Telkom Appliance Science School, Telkom University \\ Telekomunikasi Street, Bandung 40257, Indonesia \\ ${ }^{1}$ gitaindahhapsari@tass.telkomuniversity.ac.id \\ ${ }^{2}$ roychaidir@gmail.com
}

\begin{abstract}
Abstrak - Pengukuran konduktivitas merupakan bagian dari sebuah instrumen CTD (Conductvity Temperature Depth) yang digunakan untuk mengukur salinitas (kadar Garam) air atau berdiri sendiri sebagai alat ukur konduktivitas cairan. Metoda yang digunakan adalah metoda pengukuran tak kontak (contactless) dengan menggunakan sensor toroida. Sensor ini diaplikasikan dan diuji di ISRG ITB untuk mendapatkan karakteristik input atau outputnya. Adapun pengolahan data sensor adalah sebuah modul yang dirancang dengan basis mikrokontroler AT89C2051 dan program aplikasi sederhana untuk PC. Keluaran dari prototype ini dalam bentuk tegangan pada monitor untuk selanjutnya dianalisis secara grafis. Pengujian dilakukan pada sekumpulan data input berupa nilai resistansi dan larutan garam. Hasil secara keseluruhan menunjukkan bahwa perbandingan input/output menghasilkan bentuk mendekati linier. Hal ini menunjukkan bahwa alat ini dapat bekerja dengan baik dan dapat digunakan dalam menentukan konduktivitas cairan.
\end{abstract}

Kata kunci: Konduktivitas, sensor toroida, mikrokontroler AT89C2051

\section{Pendahuluan}

Air mengandung berbagai jenis material yang terlarut didalamnya. Material ini berupa zat cair, padat atau gas. Penelitian menunjukkan bahwa kandungan mineral dapat diidentikkan dengan jumlah kandungan garam terlarut (dissolve solids) yang terdapat pada air tersebut, yang biasa disebut kadar garam (salinitas).

Semakin banyak jumlah kandungan garam terlarut makin tinggi konsentrasi ion dalam larutan tersebut, sehingga salinitas suatu larutan akan menentukan daya hantar (konduktivitas listrik) larutan tersebut.

Kadar garam setiap jenis air berbeda-beda. Pada beberapa bidang sering kali dilakukan pengukuran salinitas air untuk kebutuhan penelitian. Pengukuran salinitas juga sering dilakukan diperusahaan air murni untuk memantau kualitas air murni pada produknya.

Hal ni menyebabkan dibutuhkannya suatu alat yang dapat melakukan pengukuran konduktvitas cairan yang diharapkan dapat diaplikasikan pada pengukuran salinitas air atau menentukan kualitas air.

\section{Tinjauan Pustaka}

\subsection{Konduktivitas dan Salinitas}

Salinitas adalah jumlah kandungan garam yang terdapat dalam satuan massa larutan. Satuan umumnya adalah ppt (part per thousand) atau ppm (part permillion). Beberapa satuan lain yang sering digunakan adalah persen atau gram per liter.

Pengertian dari satuan ini adalah jika suatu larutan garam memiliki salinitas 5\%, berarti dalam 100 bagian larutan, 5 bagiannya adalah garam dan 95 lainnya air (pelarut). Maka jika ada $1 \mathrm{~kg}$ larutan maka didalamnya terkandung 50 gram garam. Hal ini sama artinya dengan $50 \mathrm{ppt}$ atau $50000 \mathrm{ppm}$. Salinitas air laut berkisar antara 32-37 ppt.

TELKA, Vol.2, No.2, November 2016, pp. 70 81

ISSN (e): 2540-9123 
Konduktivitas adalah kemampuan materi untuk menghantarkan muatan listrik dari satu titik ke titik lain. Konduktivitas merupakan kebalikan dari hambatan atau resistansi. Materi atau zat yang berbentuk cair dan memiliki kemampuan menghantarkan listrik disebut elektrolit.

Kemampuan suatu larutan menghantarkan muatan listrik sangat dipengaruhi oleh kandungan zat padat yang terdapat pada larutan tersebut. Kandungan ini biasa disebut TDS (Total Dissolved Solids) yang merupakan faktor penting yang dijadikan tolak ukur kualitas air minum.

\subsection{Metoda Pengukuran}

Ada 2 jenis metoda pengukuran yang digunakan untuk mengukur konduktivitas yaitu kontak (elektroda) dan induksi contactless. Metoda yang digunakan pada penelitian ini adalah metoda tak kontak yang mengacu pada hukum Biot Savart dan Hukum Faraday mengenai elektromagnet. Hukum biotsavart menjelaskan bahwa disekitar arus listrik terdapat medan magnet yang besar dan arahnya sesuai dengan arah arus listrik tersebut. Sedangkan hukum faraday mengatakan bahwa arus imbas yang terjadi dalam suatu loop kawat tertutupberbanding lurus dengan kecepatan perubahan fluks magnetik yang dilingkupi loop kawat tersebut.

\subsection{Sensor Toroida}

Jika toroida primer dialiri arus, maka akan timbul medan magnet pada lilitan kawatan toroida primer yang disebut induksi magnetik (hukum Biot Savart). Besarnya induksi magnet (B) ini adalah:

$$
B=\frac{\mu \mathrm{o} . \mathrm{i}}{2 . \pi \cdot a}
$$

Dengan:

$\mu_{\mathrm{o}}=$ permeabilitas ruang hampa $(4 \pi .10-7$ Weber.Ampere-1. M-1)

$\mathrm{i}=$ kuat arus (Ampere)

$\mathrm{a}=$ jarak titik ke penghantar $(\mathrm{m})$

Arah medan magnet ini akan berubah-ubah jika arah arus berubah juga. Dengan demikian fluks magnet (jumlah medan magnet yang memotong bidang) pada loop tertutup disekitar toroida akan berubah pula. Sesuai hukum faraday, perubahan fluks ini akan menmbulkan GGL imbas () pada loop tertutup yang melingkari penampang toroida primer tersebut. Peristiwa ini disebut imbas elektromagnetik.

GGL imbas inilah yang kemudian menghasilkan arus induksi $\left(\mathrm{i}_{\mathrm{m}}\right)$ yang besarnya adalah:

$$
i m=\frac{\epsilon}{R}
$$

atau

dengan :

$$
i m=\epsilon \cdot \gamma
$$

$\mathrm{R}=$ Resistansi rangkaian loop tertutup (ohm)

$\gamma=$ Konduktansi rangkaian loop tertutup

Dari persamaan diatas dapat dilihat bahwa besarnya arus induksi yang terjadi tidak berbanding lurus dengan nilai resistansi melainkan berbanding lurus dengan nilai konduktansi rangkaian. Kemudian arus induksi ini akan menghasilkan medan magnet pada lilitan toroida sekunder dan prosesnya berbalik seperti pada primer. Perubahan fluks pada toroida sekunder akan menghasilkan arus yang kemudian dijadikan input rangkaian konversi. 


\subsection{Mikrokontroler AT89C2051}

AT 89C2051 merupakan salah satu jenis mikrokontroler low power yang compatible dengan keluarga intel 8051. Spesifikasi dari mikrokontroler AT89C2051 adalah sebagai berikut:

1. Catu daya sebesar 5 volt

2. EEPROM (Electrically Erasable Programable Read Only Memory) internal sebesar 4 Kbyte

3. RAM (Random Access Memory) internal sebesar 128 byte.

4. CPU 8 bit

5. Osilator internal dengan 1 microsecond instruction cycle pada kristal $12 \mathrm{MHz}$

6. Memiliki 2 buah pencacah 16 bit

7. Bidirectional I/O 15 buah

8. Interupsi sebanyak 6 buah yaitu 2 interupsi eksternal, 2 interupsi timer, 1 interupsi serial dan 1 interupsi reset.

9. Memiliki UART (Universal Asynchrounous Receiver/Transmitter)

\subsection{Perancangan Sistem dan Implementasi}

Secara umum perancangan perangkat pengukuran konduktansi diperlihatkan pada gambar 1. Sensor yang digunakan adalah toroida yang berfungsi sebagai pendeteksi perubahan arus akibat perubahan konduktivitas bahan atau larutan. Rangkaian konverter berfungsi untuk mengubah output sensor menjadi tegangan searah, menurunkan level tegangan sesuai kebutuhan ADC dan dikonversikan ke dalam bentuk digital agar dapat diolah oleh bagian pemroses data.

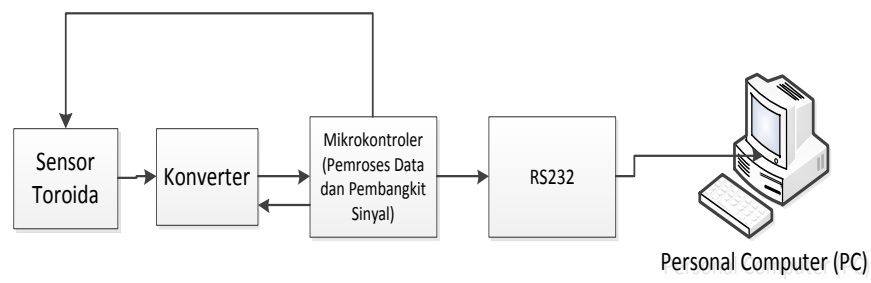

Gambar 1. Diagram Blok Pengukuran Kondutivitas Cairan

Mikrokontroler merupakan bagian pemroses data yang berfungsi menghitung dan mengolah data untuk kemudian ditampilkan pada PC juga sebagai pembangkit sinyal untuk input ke toroida. Data yang telah diproses pada mikrokontroler kemudian dikirimkan secara serial menggunakan IC MAX 232 ke personal komputer.

Bahasa pemrograman yang digunakan untuk menampilkan tegangan keluaran RS 232 adalah Bahasa C. Perubahan nilai tegangan yang terjadi berkorelasi dengan perubahan nilai konduktivitas cairan.

Adapun spesifikasi perangkat keras adalah sebagai berikut:

1. Catu Daya 5 volt dan -5 volt.

2. Menggunakan sensor toroida sebagai sensor salinitas dengan frekuensi sinyal input toroida $14,7 \mathrm{KHz}$ berasal dari mikrokontroler.

3. Nilai pengukuran yang dihasilkan adalah konduktivitas cairan dalam satuan siemen dengan batas pengukuran maksimum 0,5 siemens.

4. Nilai informasi ditampilkan pada perangkat komputer/Personal Computer (PC)

\subsection{Sensor}

Sensor yang digunakan pada pengukuran konduktivitas dengan metoda tak kontak adalah terdiri dari 2 toroida, yaitu primer dan sekunder. Kedua toroida ini dibatasi dengan kuningan yang merupakan bahan paramagnetik yang berfungsi membatasi imbas elektromagnet dari primer ke sekunder. Rangkaian sensor dapat dilihat pada gambar 2. 
Sensor terdiri dari 2 bagian yaitu bagian drive dan detection (Gambar 3). Bagian drive dihubungkan dengan sumber sinyal persegi yang dibangkitkan oleh mikrokontroler dengan frekuensi $14,7 \mathrm{KHz}$. Sinyal ini kemudian diubah menjadi sinyal gergaji oleh sebuah kapasitor pada output port mikrokontroler . Bagian detection dihubungkan dengan input dari rangkaian penyearah.

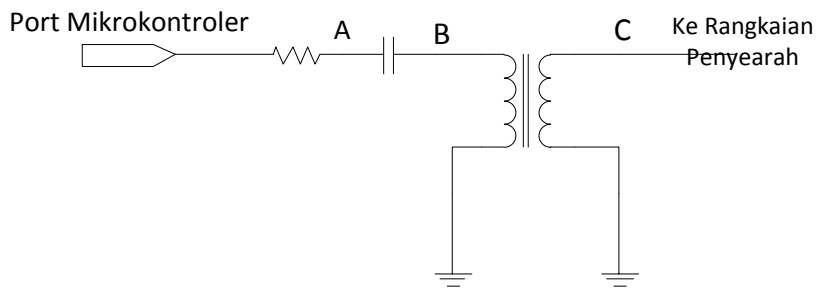

Gambar 2 Rangkaian Sensor Toroida

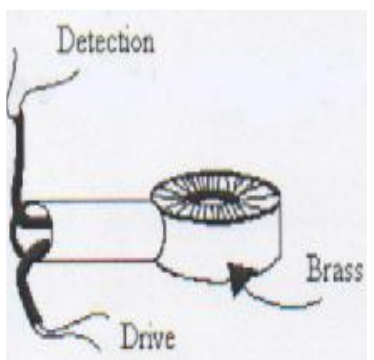

Gambar 3 Toroida

Cara pengukuran menggunakan metoda toroida ini adalah dengan mencelupkan toroida ke dalam larutan yang akan diukur dimana bagian larutan melalui pusat toroida. Toroida ditutupi dengan pelindung dari bahan plastik atau kaca agar tidak mendapat kontak langsung dengan larutan. Cara pengukuran ini dapat dilihat pada gambar 4.

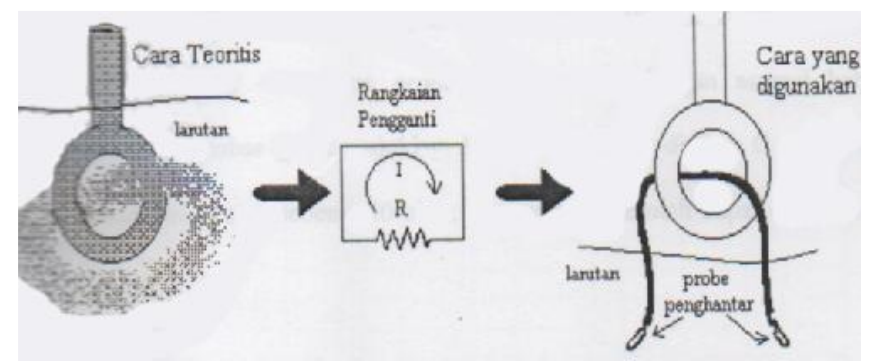

Gambar 4 Pengukuran konduktivitas menggunakan toroida

\subsection{Rangkaian Konverter}

Rangkaian konverter mendapatkan input dari sensor yang merupakan arus bolak balik. Perubahan yang terjadi pada keluaran sensor adalah pada besaran amplituda. Besaran itu merupakan sinyal AC (Alternating Current). Blok diagram Rangkaian konverter diperlihatkan pada gambar 5 .

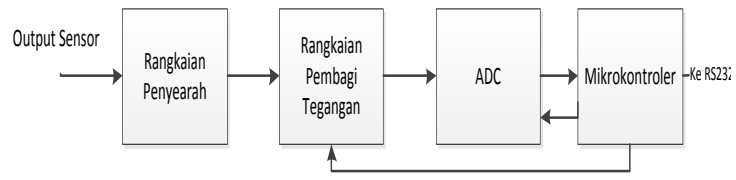

Gambar 5 Diagram Blok Konverter 
Rangkaian konversi terdiri dari rangkaian penyearah, rangkaian pembagi tegangan dan ADC (analog to digital converter). Penyearah berfungsi untuk mengubah tegangan bolak-balik menjadi searah. Rangkaian pembagi tegangan adalah rangkaian yang ditambahkan untuk menurunkan tegangan input ADC. Hal ini dilakukan karena input maksimum ADC adalah $512 \mathrm{mV}$.

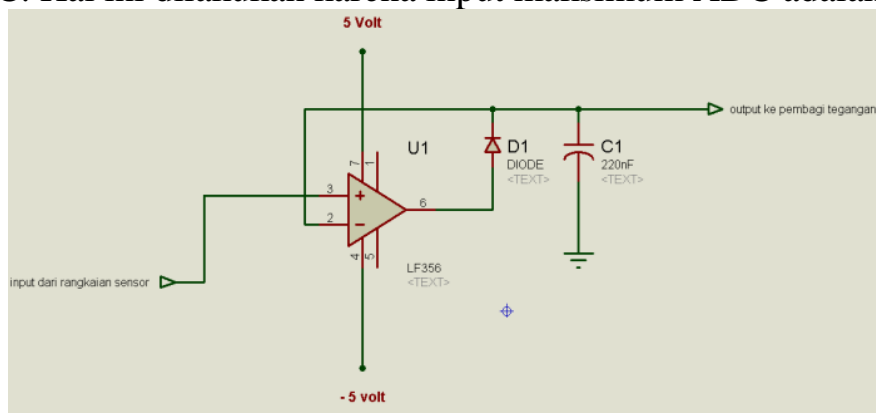

Gambar 6 Rangkaian Penyearah

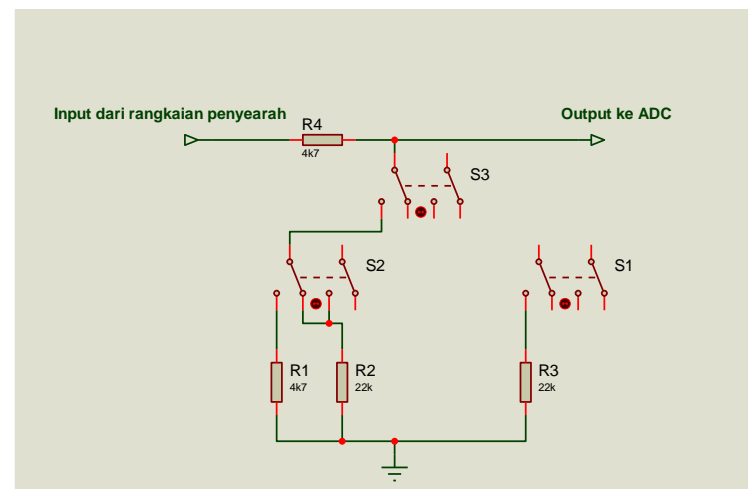

Gambar 7 Rangkaian pembagi tegangan

Rangkaian penyearah pada dasarnya menggabungkan rangkaian voltage follower dengan sebuah dioda penyearah seperti pada gambar 6. Rangkaian pembagi tegangan dikendalikan melalui 3 pin mikrokontroler yang dapat menghasilkan 3 skala penurunan tegangan. Konfigurasi rangkaian ini dapat dilihat pada gambar 7. Keluaran dari pembagi tegangan inilah yang kemudian menjadi masukan untuk ADC.

Komponen utama rangkaian ADC adalah IC MAX132DIP yang mengubah tegangan analog menjadi tegangan digital. IC ini bekerja dengan catu daya 5 volt DC dan Oscilator $32,768 \mathrm{KHz}$ dengan resolusi 18 bit dan memiliki tegangan input berkisar antara $512 \mathrm{mV}$ dan $-512 \mathrm{mV}$. Gambar 8 memperlihatkan rangkaian ADC untuk IC MAX132. Gambar 9 memperlhatkan rangkaian MAX 232.

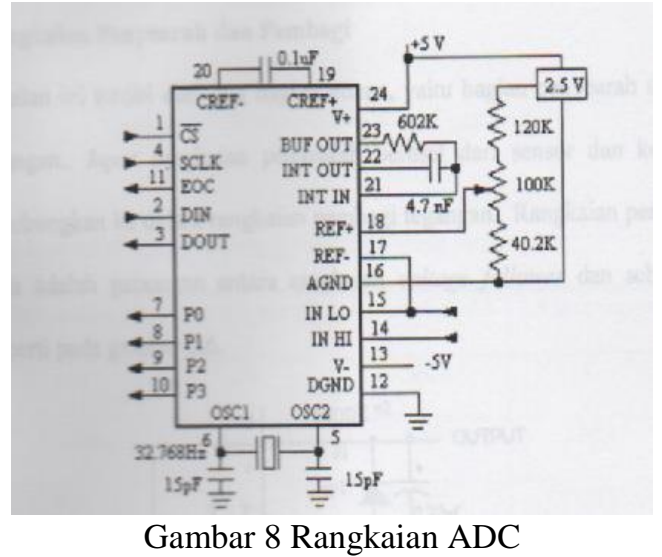

ISSN (e): 2540-9123

ISSN (p): 2502-1982 


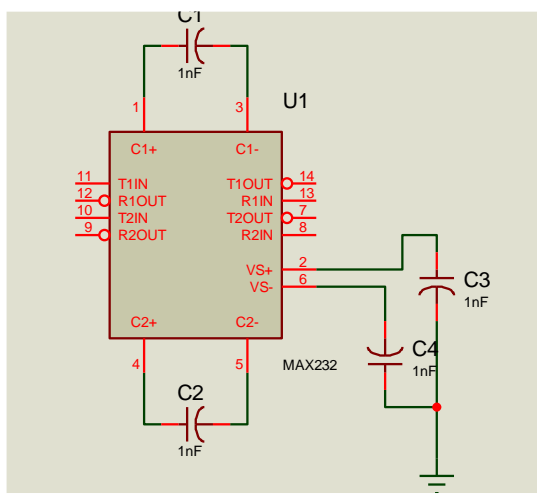

Gambar 9 Rangkaian MAX 232

\subsection{Pengolah Data}

Rangkaian pengolah data terdiri dari mikrokontroler dan program aplikasi pada komputer. Mikrokontroler berfungsi sebagai sumber sinyal input untuk sensor, pengontrol kerja ADC dan mengatur komunikasi data dengan komputer. Pemrograman mikrokontroler dilakukan dengan menggunakan bahasa assembler MCS 51 atau ASM 51 pada mikrokontroler.

Program aplikasi pada komputer berfungsi sebagai pengolah data dalam PC, mengatur tampilan dan media kontrol alat ukur. Penggunaan perangkat lunak pada bagian ini menggunakan bahasa C. Keluaran dari mikrokontroler kemudian dikirimkan ke PC secara serial, tampilan data kemudian ditampilkan pada monitor PC dalam bentuk kode atau pun bentuk lain yang diinginkan.

\subsection{Catu daya}

Rangkaian catu daya mengasilkan 2 keluaran tegangan yaitu tegangan 5 volt dan -5 volt. Catu daya 5 volt untuk catu daya IC AT89C2051, MAX 132, MAX232, AD680 dan ICL 7660 sedangkan catu daya -5 volt untuk op-amp IC LF 356. Skema catu daya diperlihatkan pada gambar 10.

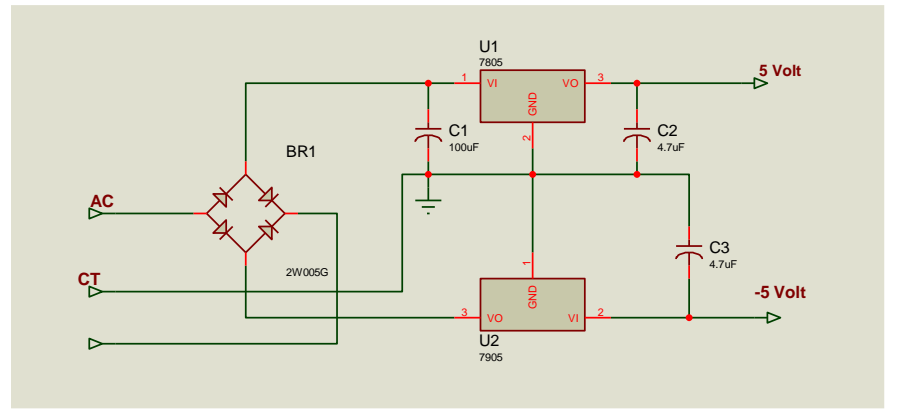

Gambar 10 Rangkaian Catu Daya

\subsection{Perangkat Lunak}

Perangkat lunak yang digunakan pada sistem pengukuran konduktivitas ini dibagi menjadi 2 bagian yaitu perangkat lunak yang bertugas mengendalikan kerja perangkat keras berbasis mikrokontroler AT89C2051 dan perangkat lunak yang mengolah data dari pengukur dan menampilkannya. 


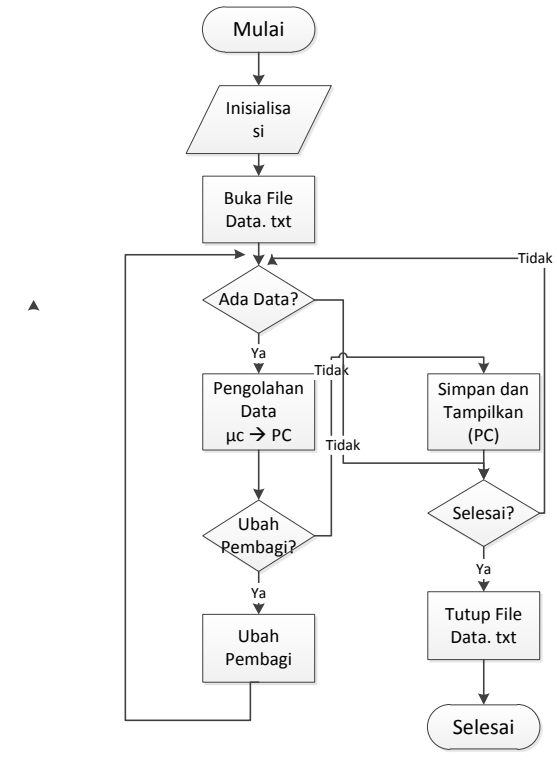

Gambar 11 Diagram Alir Program Keseluruhan

Program pertama ditulis dengan bahasa assembler Mcs51 sedangkan yang kedua ditulis dengan menggunakan bahasa $\mathrm{C}$ dan dijadikan sebagai program aplikasi pada PC. Diagram alir program sistem secara keseluruhan pada gambar 11 menunjukkan proses pada PC dan Mikrokontroler.

\section{Program Assembler}

Diagram alir bagian utama pada program assembler diperlihatkan pada gambar 12. Program ini akan dijalankan jika mikrokontroler menerima data masukan ODH dari port serial yang dihasilkan dari penekanan tombol enter pada keyboard. Setelah itu program akan menset skala bagi tegangan menjadi skala terkecil yaitu pembagi 11. Pengesetan ini dilakukan agar ADC mempunyai batas ukur 0,5 volt mampu melakukan pengukuran jika inputnya maksimum (dari hasil test input terbesar adalah 3,1 volt).

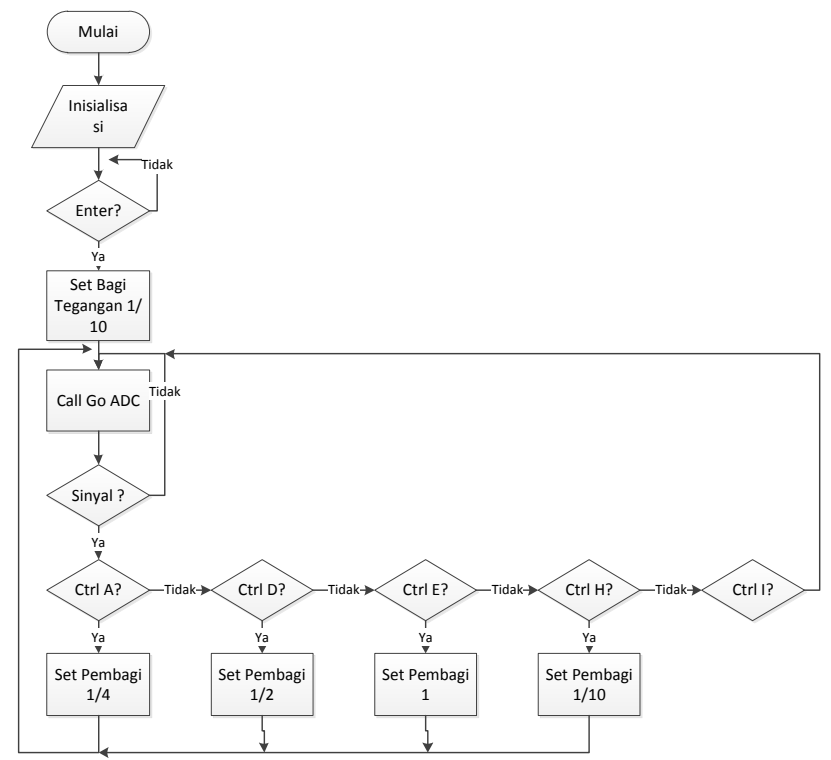

Gambar 12 Diagram alir program utama assembler 
Setelah itu program akan menjalankan program 'Go_ADC' yang berfungsi untuk mengambil input dari $\mathrm{ADC}$ dan mengirimkannya melalui serial port. Rutin ini akan terus berjalan sampai program mendapatkan masukan sinyal tertentu. Sinyal-sinyal ini yang kemudian dijadikan acuan perintah bagi mikrokontroler untuk melakukan kontrol pada saklar seperti yang telah dijelaskan pada realisasi hardware. Sinyal ctrl-I atau $08 \mathrm{H}$ berfungsi mengendalikan sistem ke kondisi awal.

\section{Program Aplikasi}

Program aplikasi menggunakan bahasa pemrograman $\mathrm{C}$ meliputi fungsi perhitungan data, fungsi pengolahan data dan fungsi format tampilan data. Diagram alir utama dapat dilihat pada gambar 13. Setelah proses inisialisasi selanjutnya membuka file 'Data.txt', file ini nantinya berfungsi sebagai tempat penyimpanan data hasil perhitungan.

Proses selanjutnya menunggu kondisi ada atau tidaknya sinyal dari port atau ada atau tidaknya penekanan tombol dari keyboard. Jika ada sinyal dari port maka akan dilakukan pengolahan data yang meliputi perhitungan data dan menampilkan data hasil olahan pada PC. Pengambilan data dilakukan 10 kali dan dilakukan pengambilan nilai rata-rata. Sedangkan adanya penekanan ctrl $\mathrm{X}$ maka akan menutup file 'Data.txt' dan mengakhiri program.

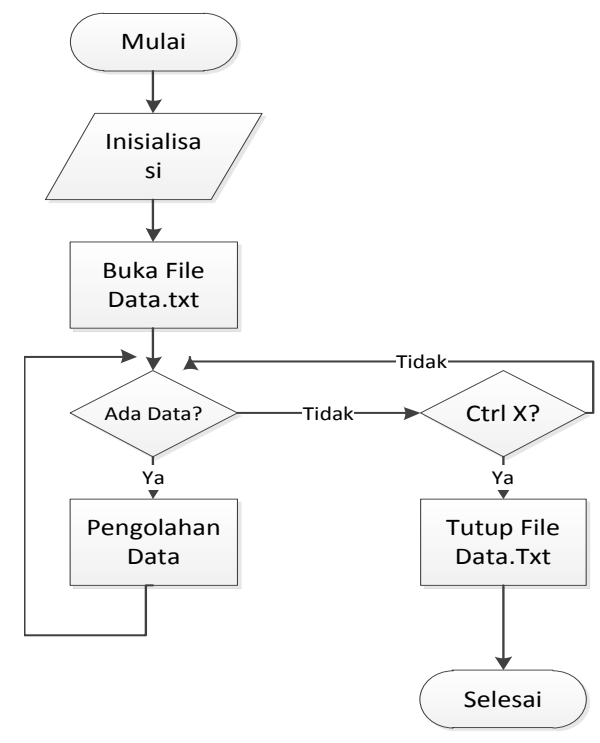

Gambar 13 Diagram alir program utama perangkat lunak aplikasi dengan bahasa $\mathrm{C}$

\section{Pengujian dan Analisis}

Pengujian dilakukan dalam beberapa tahap, yaitu :

1. Pengujian sinyal pada rangkaian toroida

2. Pengujian tegangan terhadap konduktivitas pada rangkaian konverter

3. Pengujian pengukuran konduktivitas terhadap larutan garam

Pengujian sinyal pada rangkaian toroida dilakukan pada tiga titik yaitu titik A, B dan C (gambar 14). Pengujian ini dilakukan saat kondisi konduktivitas paling besar dengan asumsi bahwa hambatan $=0$. Pada gambar 15.a dihasilkan sinyal periodik persegi dengan amplitudo sebesar 5 volt. Sinyal ini adalah sinyal yang dibangkitkan pada pin keluaran mikrokontroler dengan frekuensi $14,7 \mathrm{KHz}$.

Gambar 15.b menunjukkan sinyal keluaran kapasitor yang berbentuk gigi gergaji sebagai hasil pengisian dan pengosongan dari kapasitor. Perubahan yang terjadi hanya pada bentuk sinyal, 
tidak pada frekuensi dan amplitudanya. Sinyal keluaran sensor pada saat kedua probe dihubungkan diperlihatkan pada gambar 15.c. keluaran ini merupakan hasil induksi elektromagnetik yang terjadi pada toroida, berbentuk sinus dengan amplituda 6,2 volt dan memiliki frekuensi sama.

Sinyal keluaran sensor saat sebuah hambatan sebesar $10 \mathrm{ohm}$ dihubungkan pada probe ditunjukkan pada gambar 15.d. Pada gambar tersebut terlihat adanya penurunan amplituda akibat perubahan resistansi atau konduktansi pada kawat penghubung.

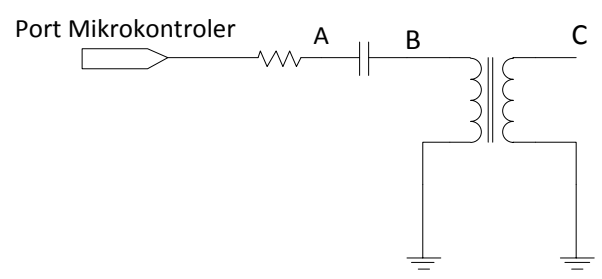

Gambar 14 Titik Pengujian sinyal pada rangkaian sensor toroida

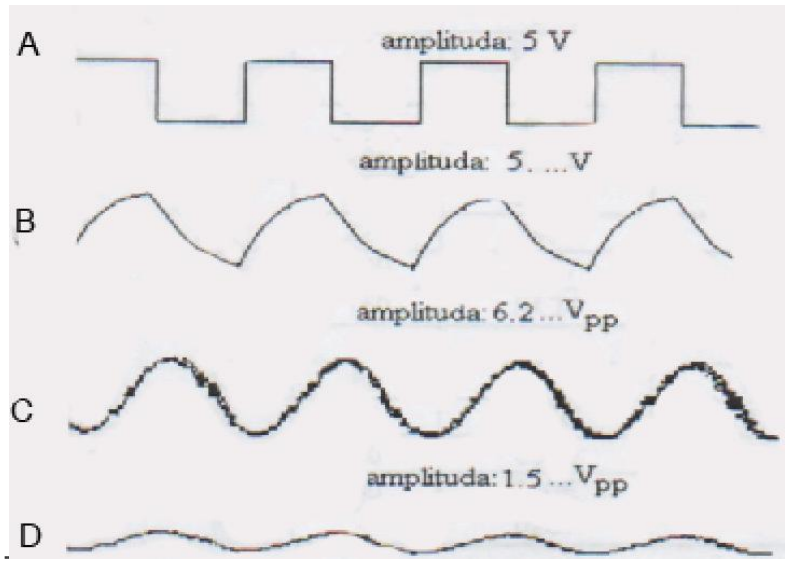

Gambar 15 Sinyal pada rangkaian sensor toroida

Pengujian tegangan dilakukan untuk menguji kerja sensor, menguji rangkaian pembagi tegangan dan ADC. Pengukuran dilakukan dengan melakukan beberapa variasi harga resistor. Resistansi 0 berarti probe berada pada hubung singkat sedangkan ada hambatan jika probe dalam kondisi hubungan terbuka. Pengujian dilakukan pada beberapa titik (gambar 16) dengan hasil pengujian seperti pada tabel 1 .

Berdasarkan hasil pengujian pada tabel 1 diperlihatkan adanya perubahan tegangan keluaran dari penyearah terhadap perubahan resistansi dan konduktansi rangkaian. Data ini jga menunjukkan kerja fungsi dari rangkaian pembagi tegangan pada tegangan yang lebih besar dari $512 \mathrm{mV}$

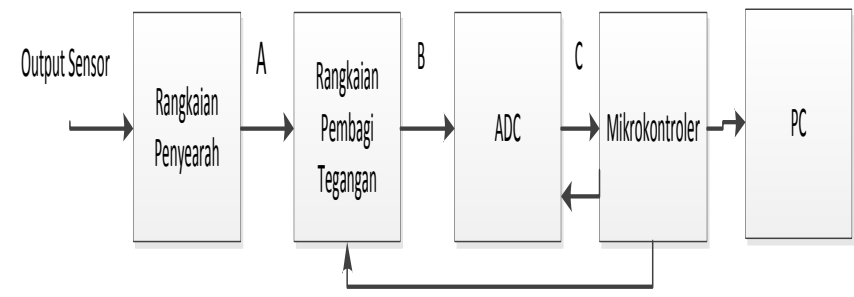

Gambar 16. Titik Pengujian Tegangan 
Tabel 1 Hasil Pengujian Pengukuran Tegangan

\begin{tabular}{|c|c|c|c|c|c|}
\hline $\begin{array}{c}\text { Resist } \\
\text { ansi }\end{array}$ & $\begin{array}{c}\text { Kondukt } \\
\text { ansi }\end{array}$ & $\begin{array}{c}\text { Tegangan } \\
\text { di A (mV) }\end{array}$ & $\begin{array}{c}\text { Tegangan } \\
\text { di B (mV) }\end{array}$ & $\begin{array}{c}\text { Output ADC } \\
\text { di C (mV) }\end{array}$ & $\begin{array}{c}\text { Output Monitor } \\
\text { PC (mV) }\end{array}$ \\
\hline 0 & $\sim$ & 3100 & 281 & A8DE & 3099 \\
\hline 1 & 1 & 3020 & 273 & A410 & 3018 \\
\hline 2 & 0,5 & 2360 & 213 & 8001 & 2358 \\
\hline 3 & 0,3333 & 1844 & 166 & $63 C 2$ & 1840 \\
\hline 4 & 0,25 & 1512 & 284 & AAAC & 1512 \\
\hline 5 & 0,2 & 1290 & 243 & 9208 & 1285 \\
\hline 6 & 0,1667 & 1110 & 209 & $7 \mathrm{D} 99$ & 1110 \\
\hline 7 & 0,1429 & 1000 & 311 & BAE6 & 1000 \\
\hline 8 & 0,125 & 894 & 278 & A711 & 894 \\
\hline 9 & 0,1111 & 810 & 251 & $96 \mathrm{D} 7$ & 810 \\
\hline 10 & 0,1 & 740 & 235 & $8 \mathrm{D} 39$ & 743 \\
\hline 20 & 0,05 & 340 & 340 & CC53 & 340 \\
\hline 30 & 0,0333 & 220 & 220 & 8436 & 215 \\
\hline 40 & 0,025 & 199 & 199 & 7797 & 197 \\
\hline 50 & 0,02 & 150 & 150 & $5 \mathrm{~A} 24$ & 150 \\
\hline 60 & 0,0167 & 113 & 113 & $43 \mathrm{E} 8$ & 113 \\
\hline 70 & 0,0143 & 89 & 89 & $357 \mathrm{C}$ & 89 \\
\hline 80 & 0,0125 & 89 & 89 & $357 \mathrm{C}$ & 87 \\
\hline 90 & 0,0111 & 80 & 80 & 3013 & 79 \\
\hline 100 & 0,01 & 60 & 60 & $240 \mathrm{E}$ & 59 \\
\hline$\sim$ & 0 & 4 & 4 & 0267 & 4 \\
\hline
\end{tabular}

Pengujian dengan larutan garam dilakukan dengan 2 buah pengukuran. Pengujian pertama dilakukan dengan menggunakan larutan garam berkonsentrasi 2-20\% dan dilanjutkan dengan pengukuran kembali beberapa nilai kapasitor yang sesuai. Hasil tegangan yang tertera pada data adalah hasil akhir dari alat ukur yang ditampilkan pada monitor (tabel 2).

Data pada tabel 1 digunakan untuk menentukan faktor pengali dalam pembuatan perangkat lunak. Sebagai contoh jika data keluaran dari resistansi $20 \mathrm{ohm}$ adalah tegangan $340 \mathrm{mV}$ dan output ADC adalah $\mathrm{CC} 53 \mathrm{H}$ atau 51187 desimal maka resolusi adalah input/output yaitu $340 / 52287=0,0065$. Bilangan ini kemudian dijadikan faktor pengali untuk menampilkan output yang benar pada monitor. Untuk pembagi tegangan lain faktornya tinggal dibagi dengan pembagi tegangan.

Secara teoritis pengukuran dengan metoda toroida ini adalah dengan cara mencelupkan toroida kedalam larutan yang akan diukur. Dengan cara itu maka sebagian larutan akan mengalir ke pusat toroida. Dengan keterbatasan bahan maka pengukuran dilakukan dengan cara menggunakan kabel yang melewati pusat toroida dan kedua ujung kabel dicelupkan kedalam larutan.

Tabel 2. Data pengukuran konsentrasi larutan Garam

\begin{tabular}{|c|c|c|c|}
\hline $\begin{array}{c}\text { Konsentrasi } \\
(\%)\end{array}$ & $\begin{array}{c}\text { Output } \\
(\mathrm{mV})\end{array}$ & $\begin{array}{c}\text { Konsentrasi } \\
(\%)\end{array}$ & $\begin{array}{c}\text { Output } \\
(\mathrm{mV})\end{array}$ \\
\hline 2 & 219 & 13 & 408 \\
\hline 6 & 294 & 14 & 420 \\
\hline 7 & 315 & 15 & 430 \\
\hline 8 & 330 & 16 & 441 \\
\hline 9 & 358 & 17 & 452 \\
\hline 10 & 372 & 18 & 462 \\
\hline 11 & 385 & 19 & 473 \\
\hline 12 & 395 & 20 & 484 \\
\hline
\end{tabular}


Dari data tabel 1 dapat digambarkan 2 buah grafik yaitu grafik output terhadap pada gambar 17 dan terhadap konduktansi pada gambar 18. Sedangkan dari tabel 1 dan 2 dapat digambarkan 2 buah grafik output terhadap persentase kandungan garam dan terhadap konduktanasi untuk nilai output yang sesuai.

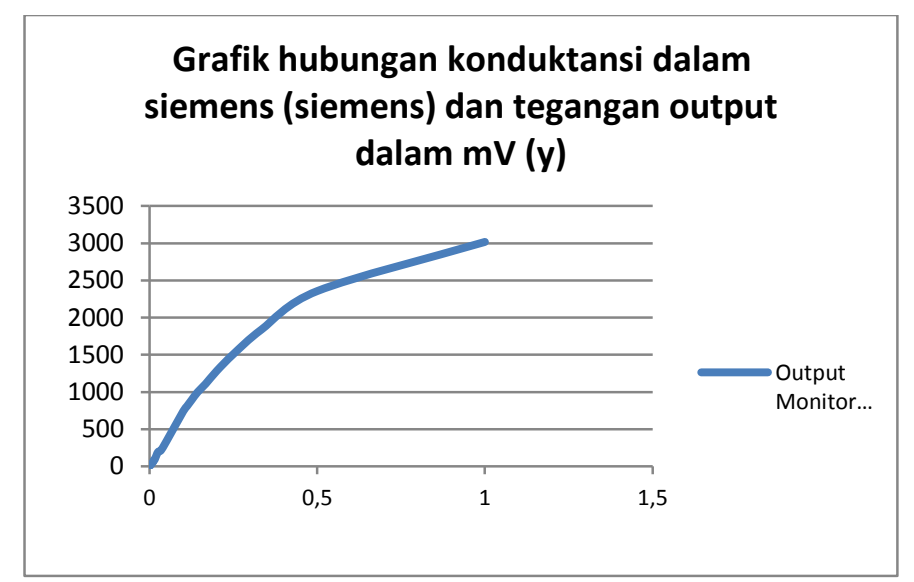

Gambar 17 Grafik hubungan konduktansi dan tegangan output

Dari gambar 17 diperoleh persamaan grafik persamaan grafik:

$$
Y=3375,3 X c+268,29
$$

Sedangkan dari gambar 18 diperoleh persamaan grafik :

$$
Y=14,019 X s+217,17
$$

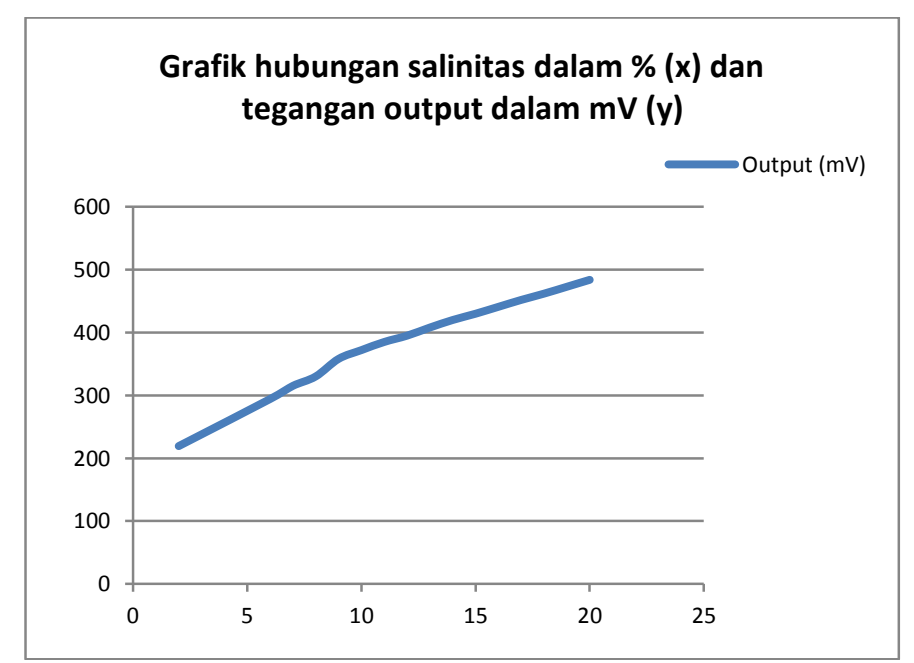

Gambar 18 Grafik hubungan salinitas dan tegangan output

Dari kedua persamaan grafik diatas maka ditentukan hubungan antara konduktivitas dan salinitas berdasarkan persamaan berikut :

$\mathrm{Xc}=$ Konduktansi (siemen)

$$
X c=0,0019 X s+0,0332
$$

$\mathrm{Xs}=$ Konsentrasi $(\%)$

Dari persamaan diatas maka dihasilkan hubungan input dan output sebagai berikut 


$$
\text { Konduktivitas }=\frac{\text { Tegangan output }+25,401}{7310,6}
$$

Dengan satuan konduktivitas adalah siemen dan satuan dari tegangan adalah mVolt. Persamaan inilah yang digunakan untuk menentukan nilai konduktivitas dari cairan pada program perhitungan PC dengan bahasa C. Perumusan ini hanya berlaku pada temperatur ruang. Untuk nilai temperatur lain perlu dilakukan penelitian lebih lanjut untuk mencari variabel suhu.

\section{Kesimpulan}

Berdasarkan hasil nilai tegangan yang dihasilkan oleh rangkaian konverter, grafik nilai tegangan terhadap konduktivitas mendekati linier untuk larutan dengan konsentrasi 2-20\% dan konduktivitas 0,01-0,1 sehingga dapat digunakan untuk melakukan pengukuran konduktivitas cairan untuk lebih lanjut diolah pada PC.

Setelah dilakukan perancangan, implementasi, pengujian dan analisa maka prototip alat ukur konduktivitas ini dapat melakukan pengukuran konduktivitas dengan melakukan konversi nilai tegangan yang berkorelasi dengan nilai konduktivitas cairan kemudian menampilkan nilainya pada monitor PC dalam batas pengukuran yang telah diujikan. Batas maksimum pengukuran dari prototip alat ukur konduktivitas ini adalah 0,5 siemens.

\section{Daftar Pustaka}

[1] Robert F. Coughlin, Frederick F. Driscoll, Operational Amplifier and Linear Integrated Circuit, Fourth Edition, Prentice-Hall, Inc

[2] Jacob Millman, Arvin Grabel, Microelectronics, Second edition, Prentice Hall, Inc

[3] David haliday, Robert Resnick, Fisika, Jilid 2 Edisi Ketiga, Erlangga, 1987

[4] I. Scott Mac Kenzie, The 8051 Microcontroller, Prentice Hall, 1995.

[5] Malvino, Prinsip-Prinsip Elektronika, Edisi Kedua, Penerbit Erlangga, 1996

[6] Rafiquzzaman, M, Ph.D, Microprocessor Theory and Application (Intel and Motorola), Prentice Hall, Inc.s

[7] Data Book IC OP-AMP. 